\title{
Sustainable Economic Growth in the Global Society
}

\author{
Elio Borgonovi*
}

\begin{abstract}
Without discussing the positive and some negative effects of economic globalization, an increasing number of researchers, scholars, consultants, policy makers added to the concept of 'globalization' the qualification of 'sustainable'.

We can define the economic sustainability as the growth of richness and its distribution that enable a larger and larger part of the world population satisfy and increase the number of their needs and a better quality of life.

The challenge for a sustainable economic growth is to elaborate theories and policies to overcome the 'free global competition', towards a 'global regulated competition', without coming back to 'state economy'.
\end{abstract}

Keywords: Sustainable Value; Economic Value; Sustainable Economic Value; Sustainable Economic Growth; Global Society; Economic Globalization

\section{Premises}

During nineties of the last century and the very first years of the new millennium, economic globalization was considered a myth, a structural evolution that nobody, or very few, ignore. This was the consequence of two main phenomena :

- the crisis of the model of a'state centralized economy', that produced institutional and political effects (like the dissolution of the Soviet Union empire and of the former Yugoslavia) the adoption of the 'market system economy' by countries that maintain non democratic political systems (like China), the very low quality of life in countries that have not yet opened to the market economy (like Cuba, North Korea and other little countries);

- the enormous progress of new technologies, in particular ICT, but also in transportation, which spread information and the direct comparison about lifestyle, level of consumption, opportunity for investment and the knowledge for producing better goods and services, around the world.

\footnotetext{
* Professor of Public Management, L. Bocconi University-Milan (elio.borgonovi@ unibocconi.it)
} 
What was defined for 10-15 years as economic globalization is a process that involved some 1.5-2 billion people, at most, out of a worldwide population of more than 6 billion. So the term and concept of economic globalization is in someway misleading.

Without discussing the positive and some negative effects of economic globalization, in this paper will focus on the fact that up until 2-3 years ago, an increasing number of researchers, scholars, consultants, policy makers added to the concept of 'globalization' the qualification of 'sustainable'. The debate on sustainability is becoming crucial and at the top of the agenda of formal international meetings (example G8, World Bank meetings, etc.) and in the most prestigious global Forum or Conferences of policy makers, entrepreneurs, opinion makers. This take on globalization leaves out some relevant dark side effects related to globalization, like global terrorism, global financial and real estate crisis (July 2007 and not yet solved). There are strong signals of a risk to return to 'cold war' situation that emerged during the summer of 2008. For clarity's sake, it is helpful to start from a very rough definition of economic sustainability as: 'the growth of richness and its distribution that enable a larger and larger part of the world population satisfy and increase the number of their needs and a better quality of life'.

\section{Reminder of Some Basic Assumptions}

The economy aims to answer, in the best possible way, the needs of individuals or communities (collective goods). Economic activity exists when and where resources are limited with regard to these needs: for example, food for eating, water for drinking, clothes to repair from cold, cars, trains or airplanes to move fast, facilities to rest, etc. It can be said that the aim of economic activity is to take people out from the condition of a 'slavery of needs' and to give them the possibility to live and survive (fighting the condition of extreme poverty in the South of the world or in the poorest segments of population also in developed countries) and, most important, to guarantee them the conditions for basic human rights.

The concept of limited resources, from the other hand, is not an absolute one, but is related to many factors :

- goods are limited in nature with regard to population;

- some goods are not limited but are abundant in some territories and limited in others : this is often a cause of war for access to resources;

- the introduction of 'ownership rights' : resources are not limited but are owned by somebody (individuals, corporations, states) and this denies access to people who need them.

The basic criteria to pursue and achieve the aim of economic activity are :

- rational allocation: this means introduce and apply rules according to which goods and services are delivered to persons for whom they have an 'higher utility' (capability to answer needs) first; 
- reduction of limited resources, through the increase of productivity : better methods and use of available tools to produce more goods in agriculture, better methods of hunting, fishing or growing animals in order to have more meat, fish, milk, eggs, etc.. The industrial (and recently) the innovation Revolution have produced: more and more goods while less and less employing people, a better organization that increased the productivity in service industries and facilitated the access of a larger number of people to these goods and services;

- applying policies of redistribution driven by state intervention or private forms of solidarity.

The fundamental principle of economic rationality is that 'more economic' richness is positively correlated to higher satisfaction for individuals and communities, and that a higher level of economic need satisfaction is positively correlated to quality of life and happiness. If these principles and correlations were true or at least largely accepted when the resources were limited, both in terms of the conditions of nature and at the beginning of the modern economy (the so called 'capitalistic model'), nowadays they are increasingly under criticism for many reasons. One is the environmental sustainability, another is the distribution problem (a very few people owned a large part of economic richness while more or less 3 billion of people, according to World Bank or other International Organizations, live with less than 2 Dollars a day). Another is related to some negative effects caused by the economic organization (example people who need to travel 3 or 4 hours a day to reach the work place). Lastly, the increase of illegal or criminal behaviour of individuals who want to get more money and more wealth, as easily as possible and in the shortest possible time).

Economic activity is driven by objective conditions, the resources that nature provides and by subjective factors, the value, expectation and behaviour of person. The perception of needs is different, for example someone likes to have high speed or prestigious cars, others prefer to use money for holidays, others for buying a boat, others to buy a house in a sea side or in a mountain location. So, the 'utility for the same goods or services', that is the principle on which economy is built, is in itself not comparable among different persons. The consequence is that some rules to make explicit the intensity of need, the utility perceived from using a good or from having access to a service, are needed. Nevertheless ethical, moral, religious value of individuals and of different communities, actual behaviour are important as well. If somebody uses his/her knowledge, competencies, skills to accumulate economic richness and to live in 'luxurious way', without considering that for many reasons other persons cannot reach the minimum standard of dignity for human beings, he/she will interpret the economic rules (for example the bargaining power) in a different way from a person who pursues his/her better standard of living while helping other people to reach the same condition. The economic knowledge and economic theory developed rules that explicit economic rationality and can influence the economic behaviour of individuals, corporations, public institutions, not for profit and other institutions. 


\section{The Economic Rules}

As complexity increases, the rules become more and more relevant to influence the individual behaviour. The three key rules to operationalize the abstract economic rationality consolidated over the centuries can be summarized as follows:

- economic rationality cannot be considered as absolute, but interacts with other type of rationality (for example scientific) and with other factors (for example emotion);

- individuals must be motivated to undertake an economic activity: the assumption is that the continuous increase of the economic wealth is the engine that classic economic theory defined as 'profit';

- the specialisation of economic activities is the best way to sustain the growth and the accumulation of economic wealth;

- a commonly accepted measure must be defined in order to make comparable what is in itself non comparable. A person perceives utility, has access or use goods to satisfy their own needs and expertise effort when they produce a good or a service, and they can sell it to another person. In the modern society this common measure has been defined as the 'exchange value'. It is an indirect but objective expression of the utility for the buyers and the sacrifice for the seller.

With regard to the first rule, some theories of the bounded rationality have been developed (J. March got the Nobel prize for that) but what is more relevant are the implications for the policy makers, either at macro system level (public policies) or at the business and non business institution strategic and managerial chance, the result of economic quantitative or qualitative analysis must be considered as an information, as an input to take the right decision. On the contrary it often happens that a decision maker consider the result of the economic analysis and comparison of different alternatives as the unique (or most important) criteria to use. This is misleading and it is a consequence of the excessive weight attributed to the economic rationality and economic performance in today's culture. The problem of sustainable growth and sustainable globalization can be considered a reaction to rules and choices that in the recent past were based mainly on the concept and philosophy of 'absolute economic rationality' rather than on that of 'bounded rationality'. It is up to us, for the future to the young researchers to rethink or fine tune theories and decision making process in order to give more relevance to the 'sustainable economic value' (or growth).

With regard to the second key principle, the mind goes to the famous Adam Smith's statement 'not from the solidarity value of the baker you can have continuously the bread, but from his/her own interest': interest was considered equivalent to the utility criteria. Economic behaviour is driven by somebody who pursues his/her own profit having the attitude to accept the risk for the future results, that are not guaranteed, and the right knowledge, competencies, capacity to 'combine' in the production factor better than any other : this is the entrepreneur.

As knowledge develops due to accumulated experience coming from practice or through scientific process, communities become larger and larger and interact 
among themselves. Economic activity becomes more and more complex and is organized applying the principle of specialization.

That means that the overall economic process is divided in different phases :

- production;

- trading;

- consumption;

- saving;

- investment.

Production is the phase in which goods present in nature are collected and transformed in order to increase their utility, their attitude to answer in a better way to the person needs. As scientific knowledge progresses some goods that are not present in nature are produced.

Trading means to convey goods from where they are abundant (low utility), to other places or communities where they are limited or don't exist at all, so they have a higher utility. This is the phase that creates connection between producer of goods and those who need them. Trading increases economic value thus contributing to the increase in the utility of goods and services.

Consumption is the phase in which people use goods and services to answer their needs, to meet their expectations, some scholars today say to pursue his or her dreams. So consumption processes generate benefits that are perceived by the person and that contribute to his/her wellbeing as individual and as community.

Saving means not to use goods and services to answer a present need in order to preserve capability to answer future needs. So, saving processes in someway generate present sacrifice in order to reduce the uncertainty for the future and in order to support the expectation of a better standard of life for the future. Saving is and can be high during the life period when people have high income or revenues and only for them. People with low level of income and revenues have less or no opportunity to save.

In effect, the reason why and the aim pursued by saving are not only the willingness to transfer the consumption path in different period of life, but also represents the willingness to increase revenue and income opportunities. This objective can be pursued and obtained through an investment process that, with an oversimplification, means to lend, to give the use of a part of the accumulated economic wealth to other people or to develop another activity.

An employee who saves for his/her future salary can lend it, meanwhile can buy an house in order to get a rent, or can buy shares of a company to get interest and increase the total income of the family. An employee can accumulate savings in order to start his/her autonomous and independent activity, by becoming an entrepreneur, from which higher revenue is expected. An entrepreneur can save part of his/her profit and invest it to develop new entrepreneurial activities.

Another basic key rule of the modern economy is related to the measurement process. Till now the term of utility, sacrifice, expectation, value of goods and services can be operationalized only if a common and agreed unit of measure 
exists. In the modern economy based on the 'market model' this commonly agreed measure has been defined as the 'exchange value' expressed in monetary units. When a person or a corporation decide to exchange something they define what to exchange (a car, a bicycle, a dress, a diamond, a glass, a computer, a software, the right to sing a song, etc.), the date when the good is transferred or the service is delivered, the quality standard, the support in case of malfunctioning and the price'. The last one can be defined as the unit of money (in the past a good commonly accepted to regulate exchanges were pieces of gold, today a piece of paper or a coin is legally recognized to regulate exchange processes) : this is the measure of the economic value.

The quantity of money is considered an expression of the economic richness because with money a person can buy specific goods or have a specific service delivered (for example a flight from London to New York or a wellness treatment). This is true at the condition that specific goods or services are available because if somebody has money but the goods are not available he/she owns nothing. The introduction of money helped the development of the economy, but at the same time raised new aspects of the economy that become more and more relevant to the globalization process.

Two of them are particularly relevant. The first is the relation between real economy (quantity and quality of real goods and services) and financial economy (the amount of money). Leaving out the problems of the inflation, this relation is quite relevant because from one hand it affects the person's attitude and value and from the other hand impacts the distribution of decision power among individuals and countries. The impact on behaviour, the complex mechanism of the modern economy (the creation of banks, of stock exchanges and in general financial markets) increased the opportunity to 'generate money from money and not from labour or entrepreneurial activity'.

$\square$ For example, if somebody buys a share of a company at a unit price of 10 Euros or Dollars and after a month or a year, due to general expectations, share trading and other factors, the price increases to 30 Euros or Dollars, the investor perceives a 00\% return on investment, even if the productivity and the long term profit trends of the company do not justify this big increase. Those who accumulated money have much more opportunity to 'invest money'. They can use their time, their knowledge, their professionalism, to increase this richness.

Of course the investor risks that the value of the share will decrease and might lose his savings. What happened in the last decade is that the financial economy grew far faster than the real economy and that the globalization is easier for technical and behaviour reasons, in the financial markets. The result was that the globalization pushed and facilitated the development of the real economy (more goods and services are available for a larger number of people than 2 or 3 decades ago) but sustained a much higher development of the financial economy, the so called 'paper economy'. This unbalance caused 3 or 4 crisis in the last 10 years that have had a global impact, the last one is the subprime financial crisis. 
The second effect is the accumulation of financial richness that changes the balance of power. Workers, professionals (engineers, physicians, etc), entrepreneurs have less power to influence their choice than in the past, while, financial institutions have a sveat deal of power to influence the real economy choices. The booming and the subsequent crisis of financial markets have a sudden and direct impact on growth, stagnation, recession of the real economy, that means of real goods and services produced and consumed.

\section{Systems of Rules}

Basically there are two systems of rules for regulating the economy. One is generally defined as the 'market system' the other the 'public regulation' one. The first is basically built on the principle that individual has large freedom to decide about production, trading, consumption, savings and investment processes. The second one is basically characterized by the presence of choices that are made by political bodies (the Parliament, the elected Assembly, at regional and local level, and Government that create constraints or incentives for the different economic processes).

If we exclude the model of the tightly regulated economies of the communist or other authoritarian regimes, it can be stated that in western countries with a politically democratic system, there are 'market systems' with different levels (extension) of public regulation. In effect the 'market system' is quite a generic definition, because it is defined by a number of variables: type of activities, the number of subjects involved, the possibility to substitute one good with another, the diffusion of information and transparency, the different bargaining power. In the economic transactions some different typologies of market have been defined by economic theory. A general accepted distinction is between:

- the USA 'market competition', much more rooted (and so regulated) on the priority and positive effects of economic motivation as a driver of personal behaviour and the positive effect of 'economic rationality';

- and the continental Europe 'market system' where public regulation is more extended and runs deeper as a consequence of the Welfare State concept.

Historically, in continental Europe some needs or some services like primary or secondary education, social services, health services are so relevant from a social point of view to motivate that they need to be guaranteed by public intervention (financed through taxation) or through some constraints or incentives to individuals, corporations, banks, etc. The 'free market competition' principle, on the other hand states that the willingness or the need to compete is the condition for continuous improvement of any economic process (production, trading, consumption, saving, investment), in that it guarantees economic and social flexibility, mobility, productivity and promotes the merit and professionalism with an overall benefit from a social perspective.

The European 'market models', (the use of plural is due to the fact that each European country is different), are less confident about self regulation and on the positive selection effect of the 'market' itself. To be more precise, the European economic culture, based also on historical experience, doesn't rely on the fact that 
self regulation always works and is convinced that self regulation and selection processes do not always have positive effects. If some conditions and public regulations are not respected, self interest influences behaviour and economic rationality in a way that can produce socially unacceptable effects. For example the poorest part of the population cannot answer basic needs. The European market systems are more or less largely affected by the model of the Welfare State. It can be said that European market systems are qualified by a balance between 'free market rules' and economic rationality on the one hand and the social and political willingness to guarantee some needs as citizenships rights.

The USA 'market economy' is much more related to the presence of a large domestic consumption market and reinforced by the creation of a larger market through the development of international trade. The European market system is much more linked to the peculiarity of the single National State model (regulation and social behaviour). The policy effort to create a single European market, began in the seventies and eighties and accelerated in particular during the nineties of the last century and the beginning of the new millennium its purpose was to help to strengthen the trust in the positive effect of the market system that, for the technical aspects was adopted also by the previous Soviet empire (that crashed at the end of eighties) and by China. It must be underlined that these States adopted the 'market system' in the economy, without a correspondent evolution of other political and social aspects of democracy. In these and in other countries the economic market freedom was accepted, without the introduction of other basic principles for the society substantially (not only formal) political freedom and the human rights regulation.

\section{The Economic Globalization Process}

The condition and the base for the economic globalization process that started at the beginning of nineties and then grew rapidly, can be summarized as follows :

- the dissolution of the 'state economy' because it demonstrated a far lower productivity compared to the 'market economy' and increased the gap either in terms of the quantity and quality of goods and services produced, or in terms of quality of life or sustaining the military confrontation;

- the new opportunity to benefit from 'international specialization' of countries and geo-economic regions rapidly increased the international trade and was also favoured by the new international agreements and rules mapped out by the WTO;

- in particular international specialization was related to opportunities to 'produce' goods and services in countries with a very low cost of labour (and in general cost of production) and the opportunities to create new large markets in developed areas or in rapidly developing countries (the upper part of China, Russia, Brazil and India);

- the technical knowledge, international rules (agreements) and behaviour that enable to an increase in the mobility of goods and services, people and financial capital to support consumption and production (unfortunately financial speculation too), information, knowledge (for example increasing 
mobility of students at the undergraduate, graduate and post graduated level;

- the unbelievable and unpredictable development of scientific knowledge and technologies.

For some 15 years the globalization process produced an increase in economic growth measured by the rapid increase of total and pro capite GDP all around the world, the opportunity given to new countries and what is more relevant to hundreds of millions of persons to reach a higher level of economic wealth and able to meet their basic needs. Some international institutions estimated that in the last 10 years about 1 billion persons have been taken out from the conditions of 'extreme poverty', even if in the last 6 months the increase of food consumption pushed back two or three hundred million people into extreme poverty. In any case the problem of the gap between the so called North of the world (developed countries or developed part of some countries) and the South of the world (the poorest countries and part of the population) has not been solved. As mentioned before, two thirds of the world population is still left out of the economic positive loop of globalization, millions of people and children still die for lack of food and basic healthcare services (illness that could be easily eradicated using drugs and scientific knowledge today, available at low cost).

The expanding trend of the globalization was and is built on some theory and policy pillars that can be shortly synthesized as follows. Opening the markets as much as possible, reducing progressively or keeping out import duties, leaving the markets rules to play their role promoting processes of liberalization, privatization, elimination of public ownership of economic activities. In effect extensive public rules generally create constraints to economic freedom, create bureaucratic obligation and reduce the overall productivity of economic 'agents' (consumer, producer, trader, financial institution). For sure some public rules and policies must be maintained to guarantee the sovereignty functions and the legacy without which no modern economic activities can be taken. The role of the State or other public institutions must be contained in producing collective goods and services, strengthening the material and immaterial infrastructures, controlling directly or indirectly the strategic activities of each country. Strategic activities are those without which the independence, autonomy and, for some politicians the population, the prestige, can be at risk.

As the open and free market become bigger and bigger the production costs decrease all around the world, the producers with lower productivity and higher costs are pushed out of the market and substituted by other producers. From these selection processes, the consumers all around the world get benefits from lower and lower prices, an increasing number of world population enter into the 'economic circle', that means increase their earnings and economic wealth becoming new consumer-customers.

Following the above assumption of the 'virtuous circle' of the globalization, some researchers and scholars proposed some theories based on the following rational: the increased economic growth and wealth will also favour the transition of socio-political and institutional systems towards the model of western liberal 
democracy. I have more than some doubts about this interpretation and recent events seem disconfirm this theory.

\section{Why the Sustainability Aspect Become More and More Explicit?}

As logic teaches, each human phenomena and society at large has two faces, one positive (expected improvement of life conditions) and one negative (unexpected and unsatisfactory effects) with regard to some objective and explicit aims. The challenge for progress is to define rules and to promote actual behaviour that makes the positive effect greater than the negative one in global term and for each person. In other words the so called win-win policy.

The main signals that the economic globalization was and is not an easy process and must be carefully managed have been loud and clear more than once in the last 15 years.

First of all, lets look at the 'bubble' effect. Once some positive processes stop suddenly (example increase of the stock exchange or increase in real estate value) and a crisis starts in some part of the world, it extends rapidly to the entire global system and sometimes become worse elsewhere than it was at the origin. In the last 15 years the world experimented the 'new economy bubble', the far eastern countries financial institutions 'bubble', the 'Russian bubble', the 'Argentina default bubble', and last, and most severe, the subprime and financial market crisis 'bubble' that appeared explicitly in July 2007. This last crisis is far from being solved and seems to be very risky one for the future of the 'globalization process' if the assumptions and the rules accepted as a dogma in the past 15 years will not change.

An increasing number of outstanding researchers, scholars, policymakers, global corporation managers, international relations experts are convinced that there is a need of 'deep rethinking' of the economic theories, policies, rules, behaviour, evaluation system of what is the role of profit as the unique or most important measure of success of a business, a company and the GDP as a measure of wealth of the nation. They also argue that there is a direct correlation between economic wealth and individual and communities welfare and wellbeing, between ownership and use (and abuse) of goods and services, between perceived satisfaction (or utility) in the short and long run and happiness.

The main factor that generates the weakness of the globalization path or model that prevailed till now can be summarized as follows. First of all, the 'market economy model' prevailed on the 'State economy model', the western countries market model, rules and economic processes structure could simply be transferred to not yet developed countries taking advantage of the lower production costs. This strategy, not related to the development of democracy and human, political and social human rights demonstrated to be successful in the short run but generated weaknesses in the medium and long run.

The underlying conceptual framework, with some simplification is : in the new international specialization of economic activities the new developing countries will be the 'wild' provider for the labour intensive and low knowledge content, while western developed countries will compete in the segment of high knowledge 
contents, innovative products, luxury or top quality segments of the market. This happened especially during the nineties, but recently countries like China, India and Russia became more and more competitive. They developed their own knowledge intensive mass and innovative industries, even if they are not yet extremely competitive in some high quality, fashion and design and creative industries.

As the globalization process took place, without any substantial change to the consolidated western economic model, the main results were :

1. high rates of growth in new developing countries and the creation of a high surplus in their balance of payments;

2. this surplus added to the surplus accumulated by countries owning oil, gas and other strategic raw materials;

3. an incredible transfer of economic wealth and economic power from the USA, Europe and other western countries to China, India, oil, gas and raw material countries;

4. high and increasing concentration of economic wealth and richness in the biggest new developing countries where some thousands of individuals or families became in just a few years extremely rich. Some will enter in the ranks of the richest people in the world, while there is a fairly limited middle class and most of the population are very poor (China, India, Russia, oil, gas and raw material providers).At the same time, global competition produced similar concentration effects, even if less visible for the time being, in the western countries. The middle class is being squeezed and the poor population is increasing;

5. an enormous and abnormal development of the financial markets and economy generated an unbalance between the real economy (value of real goods and services) that during the years became tiny in comparison to the financial economy (book value of new economy company, booming of the value of shares sometimes related to unfair financial behaviour, the creation of financial products, like derivatives, that are based simply on expectation, high risk transactions sustained by high availability of money and liquidity.

Last but not least the globalization was characterized by limited awareness of environmental pollution problem, the imbalance between strong economic power that is global and institutional, political and social power of countries and government with exception of the biggest ones (USA, China, Russia, etc).

\section{From Generation of Economic Value to Generation of Sustainable Value}

Everybody knows that it is easier to analyse models than propose innovative and better solutions. One suggestion is related to the role of rules. In effect rules are the 'mediator' between individual genetic characteristics and attitudes, individual basic values like egoism, altruism, ethical, moral, embedded culture, experience and actual behaviour. Basically in the national State during centuries (in some cases) and decades (in others) a balance was established among different types of rules, in particular legal (commonly accepted or refused behaviour), political power exercised by a limited number of persons (elected members of Parliament, Regional and local Council and elected administrators like Mayor, Governor, 
President of the Republic) on behalf of the entire population, economic (related to the economic rationality and increase of productivity). These different rules interact and act directly as a global system on the actual behaviour of individuals, socially organized groups, institutions (like families), business, public administrations, not for profit institutions, associations (see the following table).

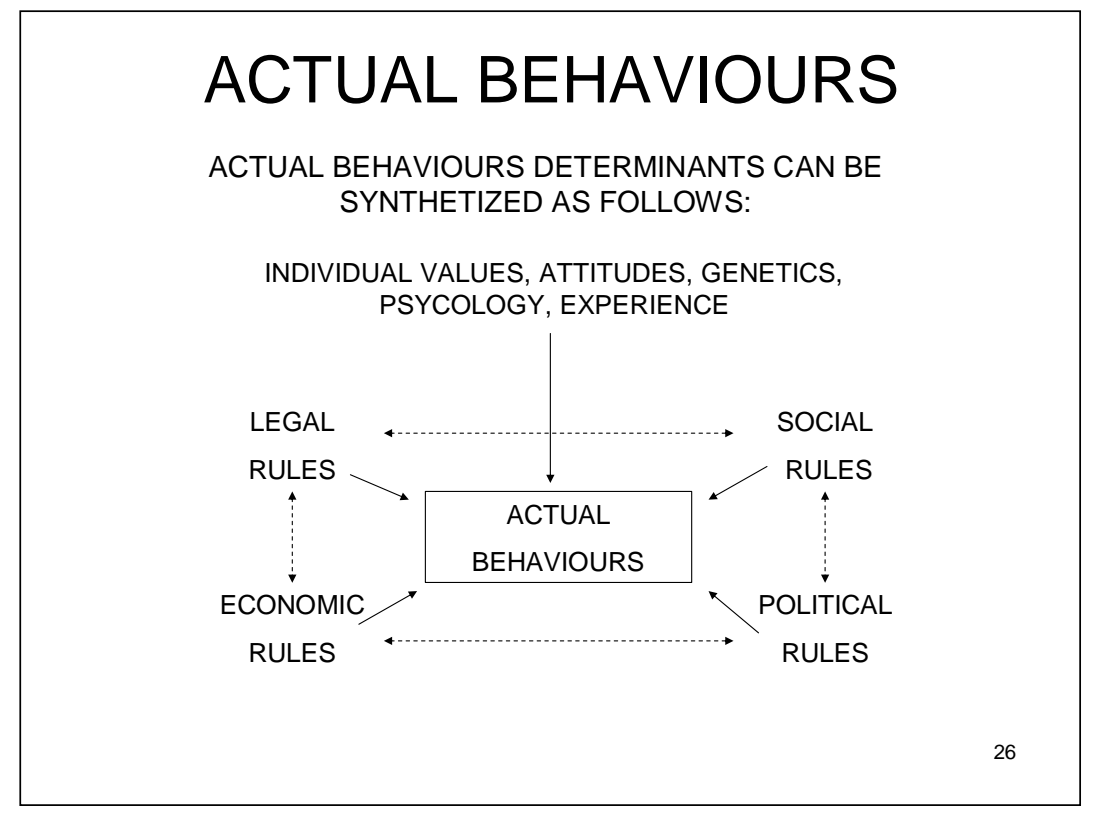

The economic globalization broke down this equilibrium (it was irrelevant whether it was positive or negative) in very few years. Market rules and production, trading, consumption, saving and investment, rules diffused rapidly and became pre-eminent vis à vis the social, legal and political rules or consolidated application of them. In some cases, take China and Russia, political rules and power still stood strong and influenced the economic process. So the self interest and economic accumulation become prevalent criteria and economic richness became in some way the benchmark for actual behaviour. Everybody tries to become richer and richer, only a few succeed. Most of the population is exposed to a lifestyle of life that they cannot afford or try to get through debts. Moreover market self regulation, the trust or the faith of the market system supporters, has shown that it does not work. In effect it works not in the desired direction, to expand a diffused welfare, but in many cases, it worked in the opposite direction. That means it has contributed to creating a gap between the rich and the poor, between people who have many opportunities and people who have not, people who develop new knowledge, competences and skills and are highly remunerated, and people who's knowledge, competences and skills become rapidly obsolete and are pushed out of the labour market.

In conclusion it can be said that a sustainable globalization can be pursued as long as:

- stronger relations (or agreements) system will be introduced for the global market;

- at the level of single Country or geo-economics area, a new balance among legal, social, political and economic rules and powers will be re-established. 
Neither solution is easy. The recent failure of Doha Round meeting on international trade, the weakness of international and multilateral organization (U.N., EU and others), the free trade area agreements and the signature of agreements for fair competition and code of behaviour among the most important global companies in the different sectors (for example drugs or food industries) demonstrated many times to be mainly formal declarations rather than feasible ones.

The challenge is to elaborate theories and policies to overcome the 'free global competition', towards a 'global regulated competition', without coming back to 'State economy' or without reducing individual trade and coming back to protectionism.

A second line to pursue, is to introduce some rules and policies able to change the trends to have more concentration of richness and, as a consequence, a segmentation of different 'global markets':

- the top restricted market of the richest people characterised by luxury, high prices, high quality of services;

- the low cost market for an increasing part of the population in developed and developing countries;

- many niche markets for the middle class that anyway become restricted and menaced by non regulated competition.

As there is evidence:

- that satisfaction, expectations and consequently behaviour of individuals and social groups depend not only on the absolute level of consumption;

- the more segmentation and the differences there are, the more difficult it is to convince people that the economic globalization is good and sustainable for the poorest or less powerful and privileged groups. It becomes more and more evident that theories on global competition are based on more opportunities for everybody but the practical consequences of this overtime is the unequal distributions of opportunities. For some, opportunities are many and better, and for some others there are fewer and fewer and the risk of worsening their life conditions increases.

Another possible way to recover a new sustainable economic value, is to adopt policies aimed at reducing the gap between the 'book value' of assets and richness for countries, companies, banks and financial institutions, families and investors and 'the real value of them'.

The too rapid development of financial economy in the globalization process creates high risks that nowadays appear clearly as weaknesses:

- book values increased on the basis of expectations and not in relation to a fair value estimates of economics viability in the long term of real activities;

- support policies to sustain consumption that were not based on a correct evaluation (the real estate market financing and then the subprime crisis).

We already mentioned that in someway the 'market self regulation' was characterized by the 'bubble' phenomena that periodically explodes to crisis.

To reduce the risk of a global economy menaced by periodic bubbles, that until now have been controlled, but that in the future can become uncontrolled. The rule 
should be created to disincentive for highly risky economic activities that are the main cause of 'panic reaction by markets' when something does not work in the expected way.

Another problem to deal with in the near future is that of the 'sovereign funds' related to the balance of power in the international arena. Using 'sovereign funds' to contribute to solve financial crise of big financial institutions and big companies in the western countries, the states that own enormous 'sovereign funds' can get more and more influence and power in defining global international relations strategies and imposing their values and their model in many fields of the life (culture, religion and more risky military).

Last but not least, it can be said that for creating sustainable value in the global market it is necessary to re-establish a balance between the two basic principles of economy:

a) competition that is the engine for continuous improvement and a continuous increase of wealth;

b) cooperation that is the way to reduce the risk of conflicts and to avoid unacceptable gaps not only in wealth but in the distribution of power. 